\title{
Nature and adsorption capacity of banana leaf rim carbon
}

\author{
Chaithra P. and Bhat Ishwara J.* \\ Department of Chemistry, Mangalore University, Mangalagangothri-574199, India. \\ Received: 20/08/2016, Accepted: 19/10/2017, Available online: 23/11/2017 \\ *to whom all correspondence should be addressed: \\ e-mail: bhatij@yahoo.com
}

\section{Abstract}

The activated charcoal (AC) was synthesized from banana leaf rim (BLR) through three activation methods; physical (BLRC), chemical ( $Z B L R C$, zinc chloride) and microwave activation (MW BLRC). The AC was characterized using fourier transform infrared spectrometer (FT-IR), Thermogravimetric analysis (TGA) \& Differential thermogravimetric analysis (DTA) instrument and Field emission scanning electron microscope (FE-SEM). The $Z$ BLRC has better thermal stability and adsorbent character compared with BLRC or MW BLRC. The present work is confined to an investigation on the adsorption process of Malachite green dye onto BLRC,

Z BLRC \& MW BLRC. Factors affecting adsorption process were studied and results that adsorption increases with concentration of dye, agitation time and temperature. This experimental data satisfied the Langmuir adsorption isotherm model. Second order kinetics holds good for the present adsorption process. Thermodynamic parameters were $\left(\Delta H^{\ddagger}, \Delta S^{\ddagger} \& \Delta G^{\ddagger}\right)$ evaluated. Based on the characterization and adsorption experimental result it may be concluded that Z BLRC has better adsorption capacity than BLRC or MW BLRC.

Keywords: Adsorption, Activated charcoal, malachite green, adsorption kinetics

\section{Introduction}

Adsorption is a process of accumulation of gas, liquid or solid particles on the surface of a solid. The substance which is adsorbed on the surface is known as adsorbate, whereas surface on which molecules adsorbed are known as adsorbent (Adamson, 1990). Activated charcoal (AC) or carbon has an ideal adsorbent character due to the presence of surface active center (micro, meso and macro pores), surface functional groups and surface charges (Bharathi and Ramesh, 2013). Activated carbon prepared from agricultural waste materials has much importance due to low cost for its raw materials and it is environmental friendly. Researchers investigated the adsorption of environmentally harmful synthetic dye onto activated carbon from agricultural waste products such as straw, rice husk, date pit, banana peel etc. (Kannan N. and Sundaram, 2001; Malik and Saha (2003); Mahmoudi et al., 2014; Annadurai et al., 2002). The literature revealed that adsorption of malachite green onto activated carbon prepared from rubber seed coat, thespesia populnea bark, rice husk, durian seed have been studied by Idris et al., 2011; Prabakaran and Arivoli, 2012; Rahman et al., 2005 and Ahmad et al., 2014.

The present work involves synthesis of activated carbon from banana leaf rim (BLR) using three different activation methods; physical (BLRC), chemical (zinc chloride (Z BLRC)) and microwave activation (MW BLRC). The synthesized $A C$ 's (BLRC, Z BLRC \& MW BLRC) were characterized using Fourier transform infrared spectrophotometer (FTIR),Thermogravimetric analysis (TA) \& Differential thermal analysis (DTA) and Field emission scanning electron microscope instruments. The present study investigates the malachite green adsorption onto BLRC, ZBLRC \& MW BLRC. The adsorption study mainly deals with the adsorption isotherms (Freundlich \& Langmuir adsorption isotherm), kinetics of adsorption (First-order and secondorder kinetics) and thermodynamics of adsorption (thermodynamic parameters $\Delta H^{\ddagger}, \Delta S^{\ddagger}$ and $\Delta G^{\ddagger}$ ).

\section{Materials and methods}

\subsection{Activated charcoal as an adsorbent}

The activated charcoal was synthesized from the dried banana leaf rim (BLR) collected from agricultural field. In order to achieve porosity on the surface of the BLR, first it is subjected to carbonization. It results porous char but for the adsorption process this porosity has to be enhanced or activated. Therefore it is activated by three methods that are physical, chemical (zinc chloride) and microwave activation method. The physical and chemical (zinc chloride) activation in muffle furnace $\left(300{ }^{\circ} \mathrm{C}, 2 \mathrm{~h}\right.$.). Microwave activation ( $80 \mathrm{~W}, 280 \mathrm{~min}$ ) in domestic micro oven. The activated charcoal obtained so was crushed in mortar to become powder and it was sieved to $250 \mu \mathrm{m}$ to get uniform sized activated carbon.

\subsection{Synthetic dye as an Adsorbate}

The adsorbate material used in the present work is malachite green oxalate powder purchased from Sisco Research Laboratories Pvt.Ltd. Mumbai, India. Malachite green oxalate is a basic dye with the molecular structure as shown in Fig. 1. 
The Malachite green oxalate is lustrous green crystal, soluble in water and methanol. Molecular formula $\mathrm{C}_{52} \mathrm{H}_{54} \mathrm{~N}_{4} \mathrm{O}_{12}$ and molecular weight is $927.02 \mathrm{~g} / \mathrm{mol}$. The aqueous solutions of the dye were prepared in distilled water. $\lambda_{\max }$ was determined using UV-Visible spectrophotometer and is found to $618 \mathrm{~nm}$.

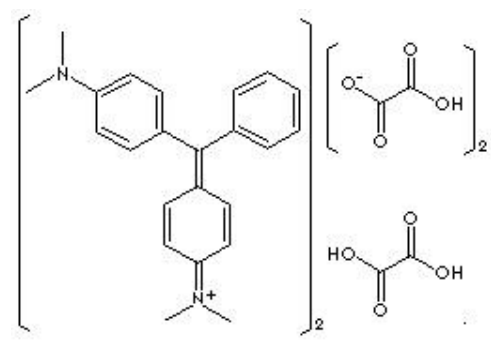

Figure 1. Molecular structure of Malachite green oxalate

\subsection{FT-IR Analysis}

Fourier transform infrared spectrophotometer (Shimadzu FT-IR Prestige-21, ATR method) was used to record the surface functional groups present in the raw and synthesized samples. The FT-IR spectra were recorded in wavenumber range of $4000-500 \mathrm{~cm}$

\subsection{TGA-DTA Analysis}

Thermal stability of BLR, BLRC, ZBLRC, MWBLRC, samples was studied by thermogravimetric analysis (TA) and differential thermogravimetric analysis (DTA) using a TASTD Q600 instrument under dry nitrogen atmosphere at the flow rate of $100 \mathrm{~mL} / \mathrm{min}$. The samples were heated from room temperature to $700{ }^{\circ} \mathrm{C}$ at predetermined rate of $20^{\circ} \mathrm{C} / \mathrm{min}$.

\subsection{FE-SEM Analysis}

The surface image was scanned using Carl Zeiss Field emission scanning electron microscope. The SEM magnification was $2.50 \mathrm{KX}$ and $\mathrm{EHT}=5.00 \mathrm{kV}$.

\subsection{Adsorption Studies}

The adsorption process was carried out by adding $0.1 \mathrm{~g}$ of activated carbon (BLRC, Z BLRC \& MW BLRC) to a three beaker containing $50 \mathrm{ml}$ of a malachite green solution of known concentration $\left(C_{0}\right)$ and was stirred for $1 \mathrm{~h}$. The concentration of dye solution after the adsorption process was measured using UV-Spectrophotometer with $\lambda_{\max }=618$ $\mathrm{nm}$. The adsorption process was studied by varying the concentration of adsorbate $C_{0}(\mathrm{mg} / \mathrm{L})$, contact time $t(\mathrm{~min})$ and temperature $T(K)$. The amount of dye adsorbed per unit mass of activated carbon and percentage obtained were calculated as follows (Zhang et al., 2016).

$$
q=\frac{\left(c_{0}-C_{e}\right) v}{W}
$$

Where $C_{0}$ is the initial concentration of dye $(\mathrm{mg} / \mathrm{L}) ; C_{e}$ is the concentration of dye in the solution after adsorption $(\mathrm{mg} / \mathrm{L}) ; V$ is the volume of the solution $(\mathrm{ml}) ;$ and $W$ is the weight of activated carbon (g).

\section{Results and discussion}

\subsection{FT-IR Analysis}

The FT-IR spectra of banana leaf rim and activated charcoal samples were shown in Fig. 2a. \& Fig. 2b. The FT-IR spectra of banana leaf rim shows characteristic peaks at 3531, 2922 and $2852 \mathrm{~cm}^{-1}$ this corresponds to intermolecular hydrogen bonded $\mathrm{O}-\mathrm{H}$ stretching vibration and $\mathrm{C}-\mathrm{H}$ stretching in alkane respectively. IR bands at $1822 \mathrm{~cm}^{-1}$ to $1637 \mathrm{~cm}^{-1}$ this is due to $\mathrm{C}=\mathrm{O}$ stretching [might be of anhydride, ester ( $\gamma$ lactone), 1,4-Quinone and carboxylic acid groups]. The stretching frequency at $1455 \mathrm{~cm}^{-1}, 1313 \mathrm{~cm}^{-1}, 1180 \mathrm{~cm}^{-1}$ and $1008 \mathrm{~cm}^{-1}$ respectively due to $\mathrm{C}-\mathrm{H}$ bending $\left(-\mathrm{CH}_{3}\right), \mathrm{C}-\mathrm{N}$ vibration (amines), $\mathrm{S}=\mathrm{O}$ stretching (sulfonamides) and $\mathrm{C}-\mathrm{O}$ $C$ stretching (ether). The IR peaks at $1000 \mathrm{~cm}^{-1}$ to $750 \mathrm{~cm}^{-1}$ is due to $\mathrm{C}-\mathrm{H}$ out of plane bending (Pavia et al., 2011; Dewan, 2010; Dyer, 1987).

The FT-IR spectra of BLRC, Z BLRC \& MW BLRC was as shown in Fig. $2 \mathrm{~b}$. The FT-IR spectrum of banana leaf rim (Fig. 2a.) showed more IR peaks than its activated carbon samples (Fig. 4.). The $\mathrm{O}-\mathrm{H}$ and $\mathrm{C}-\mathrm{H}$ stretching recorded in FT-IR spectrum of raw sample at $2922 \mathrm{~cm}^{-1}$ and $2852 \mathrm{~cm}^{-1}$ were not detected in the FT-IR spectra of BLRC, ZBLRC and MW BLRC. This indicates that structural changes observed between the banana leaf rim (BLR) and activated carbon due to the decomposition of some of the functional groups present in the raw material during activation process. Characteristic infrared absorptions of functional groups recorded in BLRC, Z BLRC and MW BLRC were shown in Table 1.

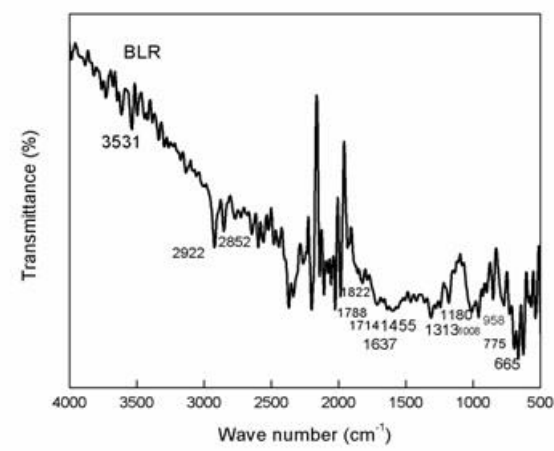

(2a)

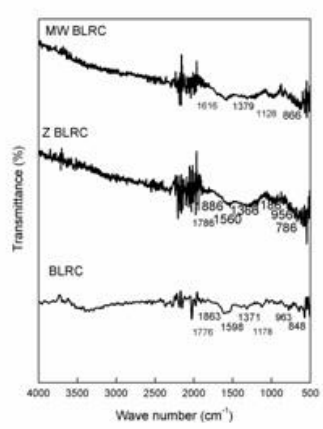

(2b)

Figure 2. 2a. FT-IR spectrum of banana leaf rim, 2b. FT-IR spectra of BLRC, Z BLRC \& MW BLRC 


\subsection{TGA-DTA Analysis}

The thermal stability of BLR, BLRC, Z BLRC and MW BLRC was studied using Thermogravimetric analysis (TGA) and
Differential thermogravimetric analysis (DTA). The TGA plot and its differential thermogravimetric plot of BLR, BLRC, Z BLRC \& MW BLRC are shown in Fig. 3.

Table 1. Characteristic infrared absorptions of functional groups recorded in BLRC, Z BLRC and MW BLRC

\begin{tabular}{|c|c|}
\hline Functional group & Intensity range $\left(\mathrm{cm}^{-1}\right)$ \\
\hline $\begin{array}{l}\text { A. Hydrocarbon } \\
\text { 1. C-H out of plane bending } \\
\text { 2. C=C stretching, Aromatic alkene }\end{array}$ & $\begin{array}{c}1000-750 \\
1600-1500 \\
\end{array}$ \\
\hline $\begin{array}{l}\text { B. Carbonyl groups }(C=0) \\
\text { 1. Ester stretching vibration, }(\gamma \text {-lactone }) \\
\text { 2. Carboxylic acids (carboxylate anion stretching) } \\
\text { 3. Anhydride stretching vibration }\end{array}$ & $\begin{array}{l}1786,1776 \\
1610-1550 \\
1886,1863 \\
\end{array}$ \\
\hline $\begin{array}{l}\text { C. Miscellaneous groups } \\
\text { 1. Amines, } \mathbf{C}-\mathbf{N} \text { vibration Primary, Secondary and tertiary } \\
\text { 2. Sulfonamides, } \mathrm{S}=\mathbf{O} \text { stretching vibration }\end{array}$ & $\begin{array}{l}1360-1310 \\
1188,1178\end{array}$ \\
\hline
\end{tabular}

The thermal decomposition of banana leaf rim was examined using thermogram curve i.e, (\%) weight loss was recorded as a function of temperature $\left({ }^{\circ} \mathrm{C}\right)$. TG curve of BLR (Fig. 3a.) reveals that till $200^{\circ} \mathrm{C}$ there was only $10.27 \%$ weight loss due to the moisture present on the surface. It has two knees before fully decomposed into ash indicating the two stability region and the decomposition of the system. The DTA curve of BLR (Fig. 3a.) also support the two degradation steps as it was seen in TG plot. The two decomposition temperature observed at $374.41{ }^{\circ} \mathrm{C}$ and $478.34{ }^{\circ} \mathrm{C}$.

The TG curve of BLRC (Fig. 3b.) reveals that only $2.77 \%$ of moisture evaporation occurs till $200{ }^{\circ} \mathrm{C}$. The maximum decomposition region of the volatile matter was observed at $300-500{ }^{\circ} \mathrm{C}$. The DTA curve showed single derivative peak at maximum decomposition temperature at $470.80^{\circ} \mathrm{C}$. This shows the presence of negligible amounts of hemicellulose in BLRC. The cellulose component degradation was found in TG curve between the temperature range $300-400{ }^{\circ} \mathrm{C}$ (Ouajai and Shanks, 2005). The final ash content was observed at $700{ }^{\circ} \mathrm{C}(13.05 \%)$. It is clear from the TG curve of $Z$ BLRC, that even at $200{ }^{\circ} \mathrm{C}$ the moisture content appeared to be high. This was mainly due to the reaction of zinc chloride with water. Thermal decomposition at 200-500 ${ }^{\circ} \mathrm{C}$ is mainly due to the decomposition of lignocellulose species. The DTA curve (Fig. 3c.) indicated the presence of two decomposition peaks at temperature $461.46^{\circ} \mathrm{C}$ and $589.29^{\circ} \mathrm{C}$.

Thermal decomposition of MW BLRC (Fig. 3d.) showed the presence of three degradation steps. There three steps indicate the evaporation of moisture (step 1: $200{ }^{\circ} \mathrm{C}$ ), decomposition of hemi cellulose and cellulose (step 2: 200 to $400{ }^{\circ} \mathrm{C}$ ) and decomposition of carbonyl groups (step3: 400 to $500^{\circ} \mathrm{C}$ ). DTA curve also reveals that the maximum decomposition temperature was at $385.09{ }^{\circ} \mathrm{C}$ and $482.10^{\circ} \mathrm{C}$.
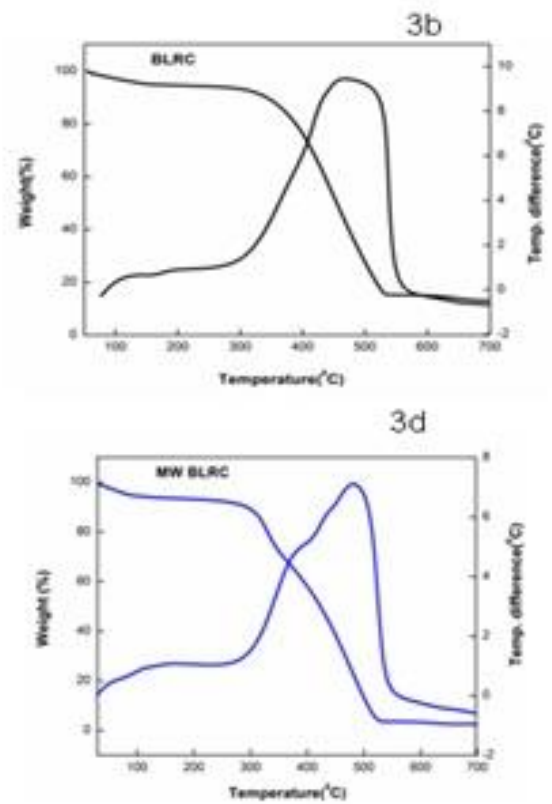

Figure 3: 3a. TGA/DTA plot of BLR, 3b. TGA/DTA plot of BLRC, 3c. TGA/DTA plot of Z BLRC \& 3d. TGA/DTA plot of MW BLRC 
Table 2: Decomposition temperature with \% weight loss obtained from TG curve.

\begin{tabular}{cccccccc}
\hline \multirow{2}{*}{ Samples } & \multicolumn{6}{c}{ Temperature of decomposition weight loss (\%) of BLR, BLRC, ZBLRC and MWBLRC ( $\left.{ }^{\circ} \mathbf{C}\right)$} \\
\cline { 2 - 8 } & $\mathbf{1 0 0}$ & $\mathbf{2 0 0}$ & $\mathbf{3 0 0}$ & $\mathbf{4 0 0}$ & $\mathbf{5 0 0}$ & $\mathbf{6 0 0}$ & $\mathbf{7 0 0}$ \\
\hline BLR & 10.27 & 11.91 & 26.31 & 73.0 & 91.97 & 92.88 & 93.93 \\
\hline BLRC & 2.77 & 5.33 & 6.69 & 23.69 & 72.45 & 85.03 & 86.95 \\
\hline ZBLRC & 11.63 & 16.37 & 17.5 & 23.31 & 41.59 & 70.14 & 86.30 \\
\hline MWBLRC & 5.51 & 6.80 & 10.81 & 41.96 & 86.82 & 96.67 & 97.47 \\
\hline
\end{tabular}

Table 3. The moisture content and ash content present in the BLR, BLRC, Z BLRC and MW BLRC

\begin{tabular}{ccc}
\hline Samples & Moisture content (\%) & Ash content (\%) \\
\hline BLR & 11.91 & 6.07 \\
\hline BLRC & 5.33 & 13.05 \\
\hline Z BLRC & 16.37 & 13.70 \\
\hline MW BLRC & 6.80 & 2.53
\end{tabular}

\subsection{FE-SEM Analysis}

The FE- SEM image of activated charcoal (BLRC, Z BLRC \& MW BLRC) before and after dye adsorption was shown in Fig. 4a, 4b, 4c, 4d, 4e \& 4f. Well-developed pores have observed on the prepared activated carbons. Chemical
$\left(\mathrm{ZnCl}_{2}\right)$ activated carbon has better porous surface than physical or microwave activated carbon. The SEM image of Z BLRC after adsorption

(Fig. 4e) showed that all the pores are filled by dye molecules.
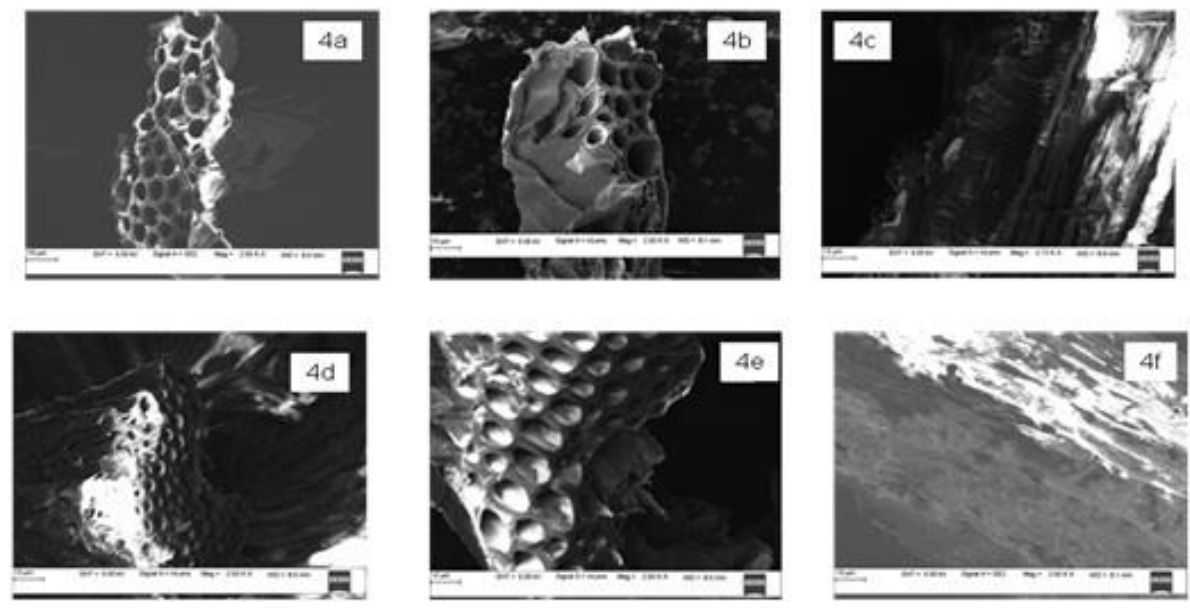

Figure 4: 4a. SEM image of BLRC, 4b. SEM image Z BLRC, 4c. SEM image of MW BLRC, 4d. SEM image of dye adsorbed $B L R C, 4 e$. SEM image of dye adsorbed Z BLRC, 4f. SEM image of dye adsorbed MW BLRC

\subsection{Adsorption isotherm}

Adsorption isotherm relates the amount of dye adsorbed on activated charcoal and the amount of dye remained in the solution at a given temperature and concentration. Adsorption of malachite green on activated charcoal was studied by varying the concentration of malachite green (20 mg/L, $30 \mathrm{mg} / \mathrm{L}, 40 \mathrm{mg} / \mathrm{L}, 50 \mathrm{mg} / \mathrm{L}$ and $60 \mathrm{mg} / \mathrm{L}$ ) at constant temperature $\left(30^{\circ} \mathrm{C}\right)$ and agitation time (1h.). Adsorption data were fitted to Freundlich and Langmuir adsorption isotherms.

The logarithmic empirical equation for Freundlich adsorption isotherm is as follows (Prabakaran and Arivoli, 2012).

$$
\log \left(q_{e}-q_{t}\right)=\log q_{e}-\frac{k_{1} t}{2.303}
$$

where $q_{e}(\mathrm{mg} / \mathrm{g})$ is the amount of dye adsorbed at equilibrium, $k_{f}$ and $n$ are the Freundlich constants, $C_{e}(\mathrm{mg} / \mathrm{L})$ is the concentration of dye at equilibrium. The plot of $\log$ $q_{e}$ versus $\log C_{e}$ is found to be non linear. Hence Freundlich adsorption isotherm is not suited for the system under study. Hence an alternate was made to fit the data to Langmuir adsorption isotherm with the following relation (Sawasdee and Watcharabundit, 2015).

$$
\log \left(q_{e}-q_{t}\right)=\log q_{e}-\frac{k_{1} t}{2.303}
$$

where $C_{e}(\mathrm{mg} / \mathrm{L})$ is concentration of dye adsorbed at equilibrium, $q_{e}(\mathrm{mg} / \mathrm{g})$ is the amount of dye adsorbed at equilibrium. $q_{m}$ or $q_{\max }$ value is obtained from the Langmuir adsorption isotherm equation and is calculated as follows:

$$
\mathrm{q}_{\max }=1 / \text { Slope }
$$

where $q_{\max }$ is the maximum amount of species required for the monolayer adsorption on the activated carbon. $b$ is the Langmuir constant. A plot of $C_{e} / q_{e}$ versus $C_{e}$ was drawn and 
found to be linear as shown in Fig. 5. From the slope and intercept of above linear plot, value of $q_{\max }$ and $b$ were evaluated.

The characteristics of Langmuir adsorption isotherm can be expressed in terms of equilibrium parameter $R_{L}$ $\left(\mathrm{R}_{\mathrm{L}}=\left(1+\mathrm{b} \mathrm{C}_{0}\right)^{-1}\right)$. Where $R_{L}$ is the equilibrium parameter, $b$ is the Langmuir constant and $C_{o}(\mathrm{mg} / \mathrm{L})$ is the initial dye concentration. Magnitude of $R_{L}$ value is an indication of favorability of the adsorption process under existing condition. $R_{L}$ value if lies between 0 and 1 then it is a favorable adsorption and if it equal to unity the plot is linear $\& R_{L}$ if zero the unfavorable adsorption (Sawasdee and Watcharabundit, 2015; Syed, 2011). $R_{L}$ values are shown in Table 4. and appears to be less than unity favoring the adsorption process.

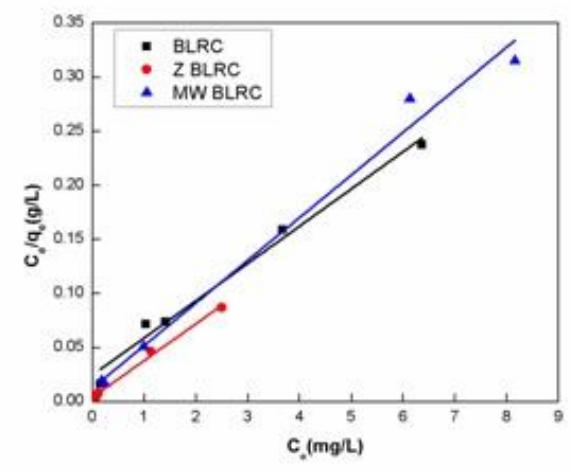

Figure 5. Langmuir adsorption isotherm plot of adsorption

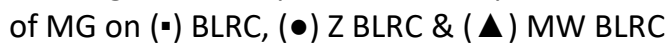

Table 4. Langmuir adsorption isotherm parameters for the adsorption of malachite green on activated carbon (BLRC, $\mathrm{Z}$ BLRC \& MW BLRC)

\begin{tabular}{|c|c|c|c|c|}
\hline Samples & $\boldsymbol{q}_{\max }(\mathbf{m g} / \mathbf{g})$ & $\boldsymbol{b}$ & $\boldsymbol{R}_{\boldsymbol{L}}$ & $\boldsymbol{R}^{\mathbf{2}}$ \\
\hline BLRC & 29.41 & 1.41 & 0.017 & 0.981 \\
\hline Z BLRC & 30.30 & 11.00 & 0.002 & 0.993 \\
\hline MW BLRC & 25.64 & 3.25 & 0.007 & 0.984 \\
\hline
\end{tabular}

Regression correlation coefficient value is found to be higher $\left(R^{2}>0.986\right)$ in this case as compared with the value obtained for Freundlich plot. This showed that Langmuir adsorption isotherm model is better fit for the present system than Freundlich adsorption isotherm. The chemical activated banana leaf rim charcoal (Z BLRC) exhibit higher $q_{\text {max }}$ value compare to other two types of AC clearly indicating the fact that adsorption capacity of chemical activated charcoal is more compared either to physical or microwave activated charcoal. The amount of species adsorbed or desorbed at equilibrium $\left(q_{e}\right)$ and it was found to between 19 and 20 (mg/g) for all the activated carbon after of $60 \mathrm{~min}$ adsorption. The adsorption efficiency of activated charcoal appear in the order Z BLRC $>B L R C>M W$ BLRC. Adsorption capacities of prepared activated carbons were compared with other adsorbent is shown in Table 5.

Table 5. Adsorption capacities of BLRC, Z BLRC \& MW BLRC compared with other adsorbent materials

\begin{tabular}{|c|c|c|}
\hline Adsorbent & Adsorption capacity, qe(mg/g) & Reference \\
\hline BLRC & 19.29 & This work \\
\hline Z BLRC & 19.95 & This work \\
\hline MW BLRC & 19.50 & This work \\
\hline Thespesia populnea bark & 95.49 & Prabakaran and Arivoli, 2012 \\
\hline Rice husk & 63.85 & Rahman et al., 2005 \\
\hline Durian seed & 476.19 & Ahmad et al., 2014 \\
\hline
\end{tabular}

\subsection{Effect of contact time and Kinetics of Adsorption}

Adsorption experiment was carried out as a function of time by keeping other parameter as constant. The time range for adsorption is with variation of agitation time 15 $\min , 30 \mathrm{~min}, 45 \mathrm{~min}, 60 \mathrm{~min} \& 75 \mathrm{~min}$. The effect of agitation time on adsorption is shown in Fig. 6.

Fig. 6. illustrates the increase in adsorption process with the increasing agitation time. Here the rate of adsorption found to vary in the order BLRC $>Z$ BLRC $>M W$ BLRC. In case of $Z B L R C$ \& MW BLRC the rate increased sharply in the beginning in time of agitation even though amount of adsorption is higher in this case. The MW BLRC exhibited the least capacity among the three activated carbons (Fig. $6)$.

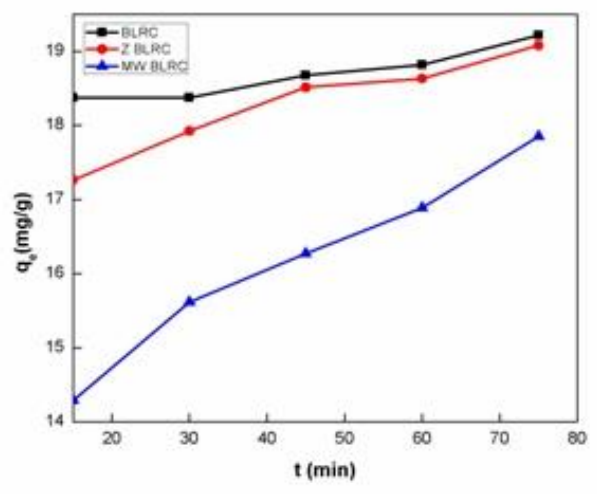

Figure 6: Effect of agitation time on the adsorption of malachite green onto activated carbon $[(\cdot) \operatorname{BLRC},(\bullet) \mathrm{Z}$ $\operatorname{BLRC} \&(\boldsymbol{\Delta}) \mathrm{MW}$ BLRC] 
The two types of kinetic model namely first-order (Reena et al., 2013) and second-order kinetic models (Sun et al., 2013) were used to determine the rate constant for the adsorption of malachite green onto activated carbon (BLRC, Z BLRC \& MW BLRC). First-order kinetic equation is as shown below,

$$
\log \left(q_{e}-q_{t}\right)=\log q_{e}-\frac{k_{1} t}{2.303}
$$

where $q_{e}(\mathrm{mg} / \mathrm{g})$ is the amount of dye adsorbed at equilibrium and $q_{t}(\mathrm{mg} / \mathrm{g})$ is the amount of dye adsorbed at time $t$ ( $\mathrm{min}) ; k_{1}(1 / \mathrm{min})$ is the first order rate constant. The rate constant is obtained from the slope of the linear plot of $\log \left(q_{e}-q_{t}\right)$ versus $t$ was shown in Fig. 7. And resulted data are shown in Table 6.

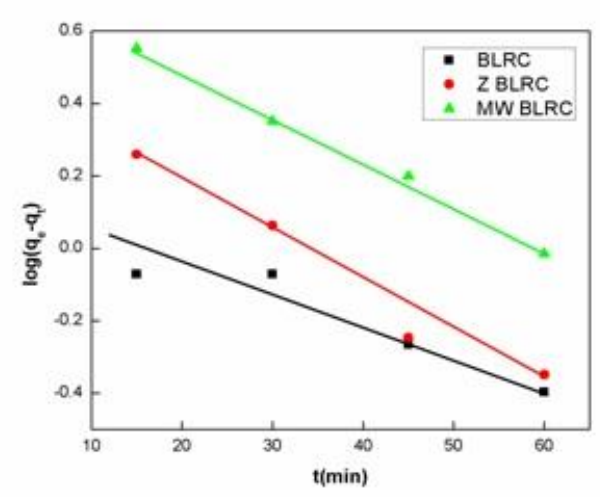

Figure 7. Plots of First- order kinetic model for the adsorption of malachite green onto activated carbon [(-) BLRC, $(\bullet) Z$ BLRC \& $(\boldsymbol{\Delta})$ MWBLRC)] at $30^{\circ} \mathrm{C}$.

Table 6. First-order kinetic parameter for the adsorption of malachite green onto activated carbon (BLRC, Z BLRC\& MW BLRC)

\begin{tabular}{ccccc}
\hline Samples & $\boldsymbol{R}^{\mathbf{2}}$ & $\boldsymbol{k}_{\mathbf{1}}\left(\mathbf{m i n}^{-1}\right)$ & $\begin{array}{c}\boldsymbol{q}_{e}(\mathrm{mg} / \mathrm{g}) \\
\text { (calculated) }\end{array}$ & $\begin{array}{c}\boldsymbol{q}_{e}(\mathrm{mg} / \mathrm{g}) \\
\text { (graphical) }\end{array}$ \\
\hline BLRC & 0.900 & 0.017 & 19.41 & 1.23 \\
\hline Z BLRC & 0.968 & 0.032 & 19.08 & 2.91 \\
\hline MW BLRC & 0.996 & 0.731 & 17.85 & 5.42 \\
\hline
\end{tabular}

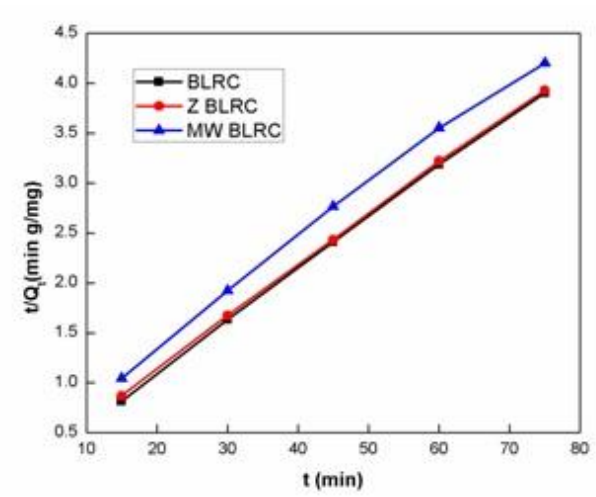

Figure 8. Plots of Second-order kinetics for the adsorption of $40 \mathrm{mg} / \mathrm{L}$ of malachite green solution on $0.1 \mathrm{~g}$ of activated carbon $[(\bullet) \operatorname{BLRC},(\bullet) \mathrm{Z} B L R C \&(\mathbf{\Delta}) \mathrm{MW} B L R C]$ for $1 \mathrm{hr}$ at $30^{\circ} \mathrm{C}$.
From the Table 6, it is clear that experimental value of $q_{e}$ much smaller than the calculated $q_{e}$ value informing that the first order rate law not holds good for the present adsorption process.

Second-order kinetics equation (Eq. (6)) was made use to evaluate second order rate constant $k_{2}$ for the studied system.

$$
\frac{t}{q_{t}}=\frac{1}{k_{2} q_{e}{ }^{2}}+\frac{t}{q_{e}}
$$

Second order rate constant $k_{2}$ was obtained from the slope of linear plot $t / q_{t}$ versus $t$ (Fig. 8).

Evaluated Second-order kinetic parameters for dye adsorption are shown in Table 7.

Table 7. Second-order kinetic parameter for the adsorption of malachite green onto activated carbon (BLRC, Z BLRC \& MW BLRC)

\begin{tabular}{|c|c|c|c|c|}
\hline Samples & $\boldsymbol{R}^{\mathbf{2}}$ & $\boldsymbol{K}_{\mathbf{2}}$ & $\boldsymbol{q}_{\boldsymbol{e}}$ (mg/g) (calculated) & $\boldsymbol{q}_{\boldsymbol{e}}$ (mg/g) (graphical) \\
\hline BLRC & 0.999 & 0.037 & 19.417 & 19.221 \\
\hline Z BLRC & 0.999 & 0.022 & 19.080 & 19.230 \\
\hline MW BLRC & 0.996 & 0.009 & 17.853 & 18.903 \\
\hline
\end{tabular}

The Table 7. Showed a comparable value between the theoretical and experimental $q_{e}$ values. Nonlinear observed in case of first order plot. The comparable value states that the system belongs to second-order kinetics.

\subsection{Effect of temperature on the process of adsorption}

The effect of temperature on dye adsorption on three system of $\mathrm{AC}$ was studied at temperatures $20^{\circ} \mathrm{C}, 30^{\circ} \mathrm{C}$, $35^{\circ} \mathrm{C} \& 50{ }^{\circ} \mathrm{C}$. From 20 to $35^{\circ} \mathrm{C}$ there was sharp increase in the $q_{\mathrm{e}}$ especially in the case of Z BLRC \& MW BLRC. Little effect was observed in the case of BLRC. These are shown in Fig. 9.

Adsorption capacity of activated charcoal (BLRC, Z BLRC \& MW BLRC) increases with temperature (Fig. 9.). Thermodynamics of adsorption of dye onto activated carbon was studied and evaluating the thermodynamic parameters such as energy of activation $\left(E_{a}\right)$, change in 
enthalpy $\left(\Delta H^{\ddagger}\right)$, entropy $\left(\Delta S^{\ddagger}\right)$ and free energy $\left(\Delta S^{\ddagger}\right)$ were calculated using the following equations (Karaoglu et al., 2010).

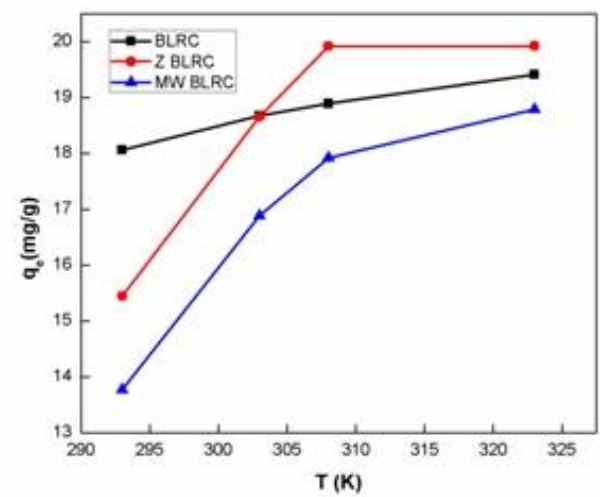

Figure 9. Effect of temperature on dye removal of malachite green by activated charcoal $[(\bullet) B L R C,(\bullet) Z$ BLRC \& ( $\mathbf{\Delta}) \mathrm{MW}$ BLRC]

$\log x=\log A-\frac{E_{a}}{2.303 R T}$

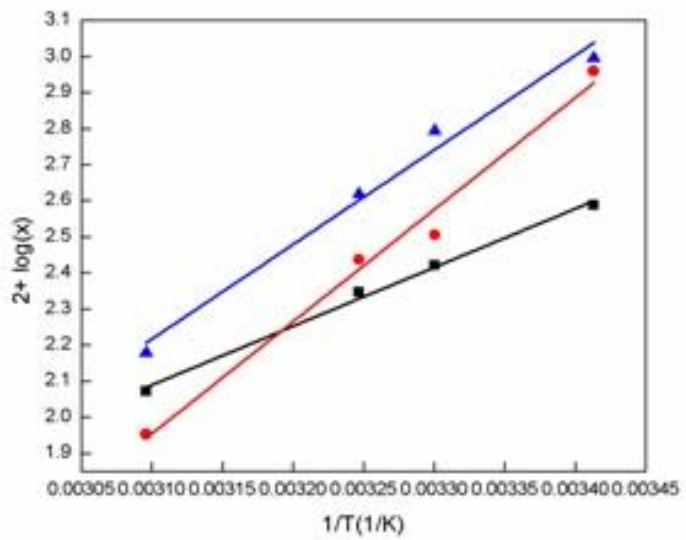

(10a) where $x$ is concentration of dye after adsorption, $E_{a}$ is the activation energy, $A$ is the Arrhenius parameter, $R$ is gas constant and $T$ is temperature $(K)$. The values of $E_{a}$ is calculated from the slope of linear plot of $\log x$ versus $1 / T$, (Fig. 10a). Further the thermodynamic parameters like change in enthalpy, entropy and free energy were calculated using absolute theory of rate expression as follows

$$
\log \left(\frac{\mathrm{x}}{\mathrm{T}}\right)=\log \left(\frac{\mathrm{k}_{\mathrm{B}}}{\mathrm{h}}\right)+\frac{\Delta \mathrm{S}^{\ddagger}}{2.303 \mathrm{R}}-\frac{\Delta \mathrm{H}^{\ddagger}}{2.303 \mathrm{RT}}
$$

Where $k_{B}$ is the Boltzmann constant, $\mathrm{h}$ is plank's constant. The change in enthalpy $(\Delta \mathrm{H} \ddagger)$ and change in entropy $(\Delta \mathrm{S} \ddagger)$ was calculated from the slope and intercepts of linear plot of $\log (x / T)$ versus $1 / T$ as shown in Fig. (10b).

Change in free energy $(\Delta G \ddagger)$ can be calculated using the Eq. (9)

$$
\Delta \mathrm{G}^{\ddagger}=\Delta \mathrm{H}^{\ddagger}-\mathrm{T} \Delta \mathrm{S}^{\ddagger}
$$

From the value of ( $\Delta G \ddagger)$ adsorption constant Kads can be calculated from the equation

$$
\Delta \mathrm{G}^{\ddagger}=-\mathrm{RT} \ln \mathrm{K}_{\mathrm{ads}}
$$

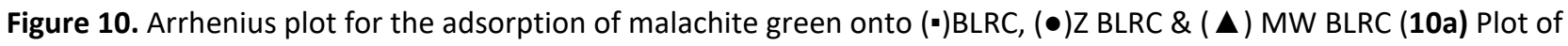

\begin{tabular}{|c|c|c|c|c|c|}
\hline Samples & $\begin{array}{c}E_{a} \\
(\mathrm{~kJ} / \mathrm{mol})\end{array}$ & $\begin{array}{c}\Delta H^{\ddagger} \\
(\mathrm{kJ} / \mathrm{mol})\end{array}$ & $\begin{array}{c}\Delta S^{\ddagger} \\
(\mathrm{kJ} / \mathrm{mol} / \mathrm{K})\end{array}$ & $\begin{array}{c}\Delta G^{\ddagger} \\
(\mathrm{kJ} / \mathrm{mol})\end{array}$ & $\begin{array}{c}k_{a d s} \\
(\mathrm{~kJ} / \mathrm{mol})\end{array}$ \\
\hline BLRC & -31.21 & -33.77 & -0.25 & 43.77 & 0.99 \\
\hline Z BLRC & -59.49 & -62.06 & -0.34 & 43.15 & 0.98 \\
\hline MW BLRC & -50.21 & -52.78 & -0.31 & 42.01 & 0.98 \\
\hline
\end{tabular}
$2+\log (\mathrm{x})$ Vs $1 / T$, where $\mathrm{x}=$ Concentration of dye after adsorption (10b) plot of $5+\log (x / T)$ Vs $1 / T$

Table 8. Thermodynamic parameters for the adsorption of malachite green onto [(•)BLRC, $(\bullet) Z \mathrm{BLRC} \&(\mathbf{\Delta}) \mathrm{MW} B L R C]$

From the Table 8. it is clear that the activation energy $\left(E_{a}\right)$ was found to be negative and are comparable for the adsorption process in BLRC, Z BLRC \& MW BLRC. The $\Delta H^{\ddagger}$ value for the adsorption process is negative which results that the adsorption of malachite green onto BLRC, Z BLRC
\& MW BLRC is exothermic. The $\Delta S^{\ddagger}$ value in the present process was found to be negative as required for an adsorption process. On adsorption the degree of randomness or degree of freedom of molecules gets decreased and the particles become stable on the surface 
upon adsorption. But the $\Delta G^{\ddagger}$ value which is expected to be negative for a spontaneous process, is not observed in the present case. This could not be explained based on the available data. Value of $k_{\text {ads }}$ is almost equal to unity indicating the equilibrium state of the system probably between adsorption and desorption.

\section{Conclusions}

Activated carbon was successfully synthesized from banana leaf rim using three different activation methods namely physical, chemical and microwave activation. These synthesized carbons were characterized by FT-IR, TGA-DTA and FE-SEM instrument. The FT-IR spectral analysis was carried out to record the functional groups present at the surface of the raw and its activated charcoal. The \% weight loss in the sample with temperature was evaluated by the use of TGA \& DTA which gave evidence to maximum decomposition composition. Surface morphology of activated carbons gets changed after adsorption of dye adsorption was noticed using FE-SEM. Langmuir adsorption isotherm was better fit for the present adsorption process than Freundlich adsorption isotherm. The present adsorption process followed the second order kinetics. Thermodynamics of adsorption also studied. The study of adsorption of malachite green onto activated carbon could be concluded that adsorption efficiency of chemical activated banana leaf rim charcoal is more compared with physical or microwave activated charcoal.

\section{Acknowledgment}

The authors are thankful to the Co-ordinator, DST-FIST Program, USIC and DST-PURSE, Mangalore University for providing instrumental facilities to carry out the present research work. The authors are also thankful to UGC-SAP, Delhi for financial assistance to carry out the present research work.

\section{References}

Adamson A.W. (1990), Physical chemistry of surfaces, Fourth Edition, Wiley science, New York.

Ahmad M.A., Ahmad N. and Bello O.S. (2014), Adsorptive removal of malachite green dye using durian seed-based activated carbon, Water, Air, \& Soil Pollution, 225(8), 1-18.

Annadurai G., Juang R.S. and Lee D.J. (2002), Use of cellulose wastes for adsorption of dyes from aqueous solutions, Journal of Hazardous Materials, B92, 263-274.

Bharathi K.S. and Ramesh S.T. (2013), Removal of dyes using agricultural waste as low-cost adsorbents: a review, Applied water science, 3(4), 773-790.

Dewan S. K. (2010), Organic Spectroscopy (NMR, IR, Mass and UV), First Edition, CBS publishers \& Distributors Pvt. Ltd, New Delhi.

Dyer J. R. (1987), Applications of Absorption Spectroscopy of Organic Compounds, Sixth Edition, Prentice Hall of India Pvt. Limited, New Delhi.

Idris M.N., Ahmad Z.A. and Ahmad M.A. (2011), Adsorption equilibrium of malachite green dye onto rubber seed coat, International Journal of Basic and applied Sciences, 11(3), 38-42.

Kannan N. and Sundaram M.M. (2001), Kinetics and mechanism of removal of methylene blue by adsorption on various carbons - a comparative study, Dyes and Pigments, 51, 25-40.
Karaoglu M.H., Zor S. and Ugurlu M. (2010), Biosorption of Cr (III) from solutions using vineyard pruning waste, Chemical Engineering Journal, 159(1-3), 98-106.

Mahmoudi K., Hamdi N. and Srasra E. (2014), Preparation and characterization of activated carbon from date pits by chemical activation with zinc chloride for methyl orange adsorption, Journal of Materials and Environmental Science, 5(6), 1758-1769.

Malik P.K. and Saha S.K. (2003), Oxidation of direct dyes with hydrogen peroxide using ferrous ion as catalyst, Separation and Purification Technology, 31(3), 241-250.

Ouajai S. and Shanks R.A. (2005), Composition, structure and thermal degradation of hemp cellulose after chemical treatments, Polymer Degradation and Stability, 89(2), 327-335.

Pavia D. L., Lampman G. M., Kriz G. S. and Vyvyan J. R. (2011), Spectroscopy, Cengage Learning India Private limited, New Delhi.

Prabakaran R. and Arivoli S. (2012), Thermodynamic and isotherm analysis on the removal of malachite green dye using thespesia populnea bark, Journal of Chemistry, 9(4), 25752588.

Rahman I.A., Saad B., Shaid S. and Rizal E.S.S. (2005), Adsorption characteristics of malachite green on activated carbon derived from rice husks produced by chemical-thermal process, Bioresource Technology, 96(14), 1578-1583.

Reena K., Goyal M., Bhagat M., Chaudhary G.R. and Sharma M.L. (2013), Influence of carbon-oxygen surface groups on adsorptive removal of malachite green dye from water, Indian Journal of Chemical Technology, 20(2), 87-94.

Sawasdee S. and Watcharabundit P. (2015), Equilibrium, Kinetics and Thermodynamic of Dye Adsorption by Low - cost Adsorbents, International Journal of Chemical Engineering and Applications, 6(6), 444-449.

Sun D., Zhang Z., Wang M. and Wu Y. (2013), Adsorption of Reactive Dyes on Activated Carbon Developed from Enteromorpha prolifera, American Journal of Analytical Chemistry, 4(7A), 17-26.

Syed S.P.S. (2011), Study of the Removal of Malachite Green from Aqueous Solution by using Solid Agricultural Waste, Research Journal of Chemical Sciences, 1(1), 88-104.

Zhang H., Wang Y., Bai P., Guo X. and Ni X. (2016), Adsorptive Separation of Acetic Acid from Dilute Aqueous Solutions: Adsorption Kinetic, Isotherms, and Thermodynamic Studies, Journal of chemical \& engineering data, 61(1), 213-219. 